\title{
Alcohol-Based Handrub: Evaluation of TeCHNiQUe and Microbiological EFFicacy With International Infection CONTROL Professionals
}

\author{
Andreas F. Widmer, MD, MS; Marc Dangel, RN
}

\begin{abstract}
BACKGROUND AND OBJECTIVE: The Centers for Disease Control and Prevention has published a new guideline on hand hygiene promoting the use of the alcohol-based handrub, but the technique was not addressed. The goal of this study was to evaluate the influence of technique on the efficacy of the alcohol-based handrub.

PARTICIPANTS: Healthcare workers ( $\mathrm{HCWs}$ ) attending a course in hospital epidemiology.

METHODS: A fluorescent dye was added to a hand antiseptic, and hands were checked under ultraviolet light after antiseptic cleansing. Data regarding the numbers of predefined fluorescent areas on the skin were collected in addition to demographic data such as age, gender, job description, and job experience. Results of the visualization test were compared with the data from microbiological samples before and after the proce-

RESULTS: Sixty HCWs were tested, $63 \%$ of whom had worked in infection control for more than 10 years. Sixty-six percent of all participants still had detectable bacteria after antisepsis. The mean $\log _{10}$ CFU reduction was 2.0 (range, 0-3.85). Twenty-five percent of all $\mathrm{HCWs}$ achieved less than $1.1 \log _{10}$ CFU. Staphylococcus aureus was isolated from 13\% (one of them being methicillin resistant) and gram-negative bacilli from $6.7 \%$. After using the alcohol handrub, one subject still remained positive for $S$. aureus. Years of experience was the single most important factor predicting antimicrobial efficacy.

CONCLUSIONS: Technique is of crucial importance in hand antisepsis. Major deficiencies were detected among even highly trained HCWs. Training should be provided before switching from handwashing to the alcohol handrub (Infect Control Hosp Epidemiol 2004;25:207-209).
\end{abstract} dure by the hand plate technique.

Hand hygiene is an important component of any infection control program. ${ }^{1}$ Handwashing with soap and water has been the standard of care in most hospitals. Recently, many hospitals have introduced a waterless alcohol handrub for hand hygiene. This can complement or replace traditional handwashing (when hands are not visibly soiled). ${ }^{2}$ The alcohol handrub is faster, microbiologically more effective, and associated with a higher rate of compliance with hand hygiene. ${ }^{3-5}$ The Centers for Disease Control and Prevention (CDC) has issued a new guideline on hand hygiene that promotes the use of the alcohol handrub. ${ }^{6}$ Therefore, hospitals may choose to emphasize the use of alcohol handrub to improve compliance. ${ }^{7}$ Handwashing ensures that almost all parts of the hands come into contact with water and soap, and formal training is likely not necessary. The most important predictor of antimicrobial efficacy for handwashing has been the amount of time spent washing the hands. However, the alcohol handrub requires good technique to apply alcohol to all parts of the hands. If several areas are frequently missed, this may potentially limit the efficacy of the alcohol handrub. Hospitals may not provide formal training when switching from handwashing to the waterless alcohol handrub. We therefore tested the influence of handrub technique on microbiological efficacy against bacteria on the skin to evaluate whether technique seemed to be a problem.

\section{METHODS}

A group of trained infection control professionals and hospital epidemiologists were tested for their technique during a training course in hospital epidemiology (August 24-27, 2002) sponsored by the Society for Healthcare Epidemiology of America and the European Study Group on Nosocomial Infection. A test center was provided during the training course. All participants were asked to check their technique with a commercially available alcohol handrub (Sterillium [2-propanol, $45.0 \mathrm{~g}$; 1-propanol, $30.0 \mathrm{~g}$; and mecetronium etilsulfat, $0.2 \mathrm{~g}$ ], Bode Chemie, Hamburg, Germany) with a fluorescent dye. A standardized questionnaire was administered to participants regarding their age, gender, years of experience in infection control, wearing of rings, standard of hygiene at their institution (handwashing or use of handrub), and country of origin. Subjects placed their fingertips on a blood agar plate, using the four fingers first, followed by the thumb in the middle of the plate; plates were processed as previously described. ${ }^{8}$ Without any training or instructions, students were asked to cleanse their hands using an amount of alcohol as seemed necessary to them. After 1 minute allowed for the procedure, they placed 


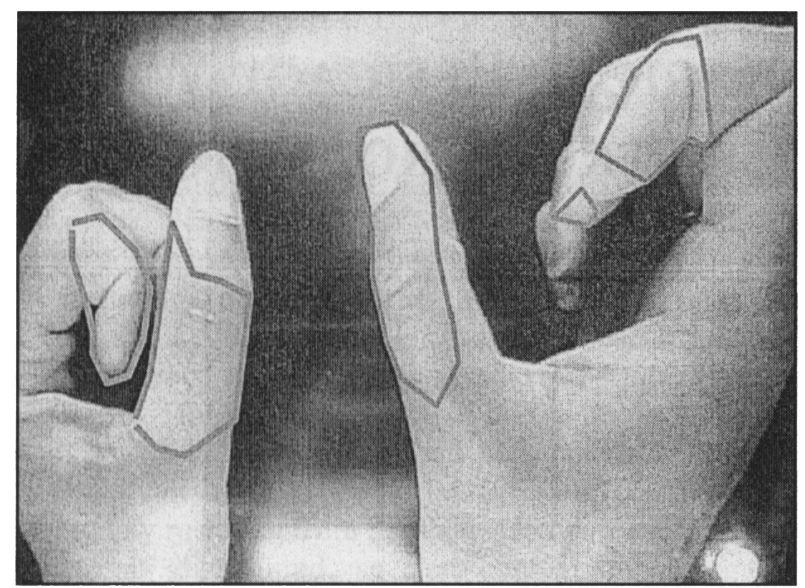

FIGURE. Areas missed (outlined) after applying alcohol handrub.

their hands in a box with ultraviolet light with a high-resolution 3-CCD digital camera attached. A beamer projected an image of the hands onto a screen; areas in contact with the fluorescent alcohol became yellow on the skin, whereas the rest of the hands remained blue (Figure). Trained infection control practitioners counted 5 different, predefined areas ( 3 $\mathrm{cm}^{2}$ ) following a written protocol. Inter-rater variability, tested in a pilot phase, was low $(\kappa>0.9)$. Each area with sufficient fluorescent dye was counted as 1 point and the sum was calculated (all areas missed, 0 points; areas in contact with the dye, 1 point); the maximum number of points in the test was 5 . After 1 minute, the students placed their hands again on a blood agar plate and were cultured as previously described. ${ }^{8}$ In brief, bacterial counts on the plates were transformed to $\log _{10}$ colony-forming units (CFU). The log reduction factor was calculated by the difference of $\log _{10} \mathrm{CFU}$ before and after hand antisepsis.

Data from the case report form were transferred to the database (Microsoft Access 1997, Microsoft Corp., Redmond, WA). Categorical data were compared using chisquare or Fisher's exact test if the expected value for a cell was below 5 . Additional statistical tests including multivariate regression analyses were performed using SPSS software (version 10.1.3; SPSS, Inc., Chicago, IL). Variables considered to have clinical importance and those having a $P$ value less than 1 were entered into the model.

\section{RESULTS}

Sixty attendees participated in the study. Two participants did not provide all data (each failing to record one variable), but microbiological analyses were available from all of the participants.

Most of the participants originated from Northern European countries and had worked more than 10 years in infection control (Table). Artificial fingernails were not detected in any of the participants, and only $5 \%$ reported any skin diseases.

The mean $\log _{10}$ CFU reduction was 2.0 (range, 0 to $3.85 \mathrm{CFU}$ ). Twenty-five percent of all participants achieved
TABLE

Microbiological Efficacy of Hand Hygiene Wrth Alcohol: UNIVARIATE ANALYSES

\begin{tabular}{|c|c|c|c|}
\hline Varlable & Distribution & $\begin{array}{l}\text { Mean } \log _{10} \text { CFU } \\
\text { Reduction Factor }\end{array}$ & $\boldsymbol{P}$ \\
\hline \multicolumn{4}{|l|}{ Age, y } \\
\hline$\leqslant 25$ & $0 \%$ & & \\
\hline 26 to 35 & $25.0 \%$ & $1.82 \pm 0.95$ & \\
\hline 36 to 45 & $38.3 \%$ & $1.89 \pm 0.91$ & \\
\hline$>45$ & $35.0 \%$ & $2.34 \pm 0.95$ & .244 \\
\hline \multicolumn{4}{|l|}{ Gender } \\
\hline Female & $55 \%$ & $1.92 \pm 0.89$ & \\
\hline Male & $45 \%$ & $2.24 \pm 0.90$ & .18 \\
\hline \multicolumn{4}{|l|}{ Job description } \\
\hline $\begin{array}{l}\text { Infection control } \\
\text { practitioner }\end{array}$ & $21.7 \%$ & $1.99 \pm 1.15$ & \\
\hline Physician & $73.3 \%$ & $2.05 \pm 0.85$ & \\
\hline $\begin{array}{l}\text { Other/no data } \\
(\mathrm{n}=2)\end{array}$ & $5 \%$ & $1.63 \pm 1.26$ & .65 \\
\hline \multicolumn{4}{|l|}{ Skin disease } \\
\hline Not present & $95 \%$ & $2.60 \pm 1.07$ & \\
\hline Present & $5 \%$ & $1.20 \pm 0.93$ & .28 \\
\hline \multicolumn{4}{|l|}{$\begin{array}{l}\text { Infection control } \\
\text { experience, } y\end{array}$} \\
\hline None & $5.0 \%$ & $1.3 \pm 1.05$ & \\
\hline$<1$ & $1.7 \%$ & 1.54 & \\
\hline 1 to 5 & $11.7 \%$ & $1.50 \pm 0.84$ & \\
\hline 6 to 10 & $18.3 \%$ & $1.94 \pm 0.90$ & \\
\hline$>10$ & $63.3 \%$ & $2.17 \pm 0.96$ & .03 \\
\hline \multicolumn{4}{|l|}{ Country of origin } \\
\hline $\begin{array}{l}\text { Scandinavian } \\
\text { countries/the } \\
\text { Netherlands }\end{array}$ & $21.7 \%$ & $1.85 \pm 1.02$ & \\
\hline $\begin{array}{l}\text { France/Spain/ } \\
\text { Italy }\end{array}$ & $5.0 \%$ & $2.67 \pm 0.32$ & \\
\hline $\begin{array}{l}\text { Switzerland/ } \\
\text { Germany/other } \\
\text { European countries }\end{array}$ & $58.3 \%$ & $2.03 \pm 0.92$ & \\
\hline Asia/Africa & $3.3 \%$ & $2.79 \pm 0.12$ & \\
\hline Others & $11.7 \%$ & $1.80 \pm 1.07$ & .35 \\
\hline \multicolumn{4}{|l|}{$\begin{array}{l}\text { Participant's type of } \\
\text { hand hygiene at his } \\
\text { or her institution }\end{array}$} \\
\hline $\begin{array}{l}\text { Handwashing with } \\
\text { plain soap }\end{array}$ & $36.7 \%$ & $2.05 \pm 0.87$ & \\
\hline $\begin{array}{l}\text { Handwashing with } \\
\text { antimicrobial soap }\end{array}$ & $16.7 \%$ & $1.95 \pm 0.82$ & \\
\hline Any alcohol handrub & $45.0 \%$ & $2.04 \pm 1.04$ & .49 \\
\hline No data provided & $1.7 \%$ & & \\
\hline \multicolumn{4}{|l|}{$\begin{array}{l}\text { Wearing a ring during } \\
\text { test }\end{array}$} \\
\hline No & $35.0 \%$ & $2.18 \pm 1.03$ & \\
\hline Noble metal & $56.7 \%$ & $1.94 \pm 0.86$ & \\
\hline Fashion jewelry & $6.7 \%$ & $1.94 \pm 1.17$ & .69 \\
\hline
\end{tabular}

$\mathrm{CFU}=$ colony-forming units. 
less than $1.1 \log _{10}$ CFU. One-third had no detectable bacteria on their skin after disinfection; for the two-thirds who had detectable bacteria remaining on their skin, Bacillus species predominated. Before antisepsis, Staphylococcus aureus was isolated from the hands of $13 \%$ of all participants; one strain was methicillin resistant. This was confirmed by a positive result on the Penicillin Binding Protein 2' latex agglutination test for MRSA (Denka Seiken, Tokyo, Japan) and detection of the mecA gene by polymerase chain reaction. Gram-negative bacilli were detected in $6.7 \%$, predominantly Acinetobacter species. No Pseudomonas species or Enterobacteriaceae were isolated. After use of the alcohol handrub, only one participant remained positive for $S$. aureus.

Sixty-five percent of the participants kept their rings on their hands while performing the test. No significant differences in the $\log _{10}$ reduction factor were observed with versus without rings. However, this area of the hands was not included in the microbiological test area. The usual type of hand hygiene at their institution was not associated with the level of antimicrobial effectiveness. Nurses, physicians, and other professionals did not differ in their hand hygiene technique (Table). Only years of job experience was a significant predictor of a good technique in univariate analyses. This variable remained significant even after adjusting for confounding variables by multiple logistic regression analysis $(P=.03)$. The participant with the highest reduction factor $\left(3.85 \log _{10} \mathrm{CFU}\right)$ was a citizen of Germany, where alcohol handrub was introduced in the 1970s.

\section{DISCUSSION}

To our knowledge, this is the first study systematically addressing the problem of technique using the alcohol handrub for hand antisepsis. The large range of reduction factors from 0 to $3.85 \log _{10}$ CFU provides ample evidence of the need for training. Before antisepsis, $13 \%$ of the participants carried $S$. aureus on their hands. Such strains may be transmitted to patients during the next patient contact if compliance or technique with hand antisepsis is poor. In addition, one participant carried methicillin-resistant $S$. aureus. This was surprising because this population is likely to be highly motivated during a training course in hospital epidemiology, and represents a selected group of healthcare workers (HCWs) with special training in infection control. Several experimental studies with artificially contaminated hands have shown that rubbing the hands with alcohol is more effective than handwashing with any unmedicated or antiseptic soap. ${ }^{9,10}$ However, only a few trials have been done in a clinical setting. ${ }^{8,10}$ None of these studies addressed the question of technique. ${ }^{7,11,12} \mathrm{~A}$ large proportion of this highly selected population of infection control professionals failed to perform appropriate technique. In addition, they had ample time to perform the procedure, lacking the time constraints in clinical practice. Given this bias, one can only estimate the performance of $\mathrm{HCW}$ s who are not infection control professionals in a busy hospital. The multivariate analysis showed that years of training was the single most important factor predicting performance in hand hygiene technique. The $\mathrm{CDC}$ promotes the use of the alcohol handrub for hand hygiene in its latest recommendation. ${ }^{6}$ Therefore, many hospitals are in the process of switching from handwashing to using alcohol handrub. The fact that years of job experience is an independent predictor for efficacy underlines the importance of appropriate training for $\mathrm{HCWs}$ before introducing the alcohol handrub into an institution.

Several limitations of this study should be mentioned. First, the microbiological technique does not allow for precise counting of CFU. The bag-broth technique allows better quantification, but is time consuming and expensive. ${ }^{13}$ Second, our method has been found to be useful in clinical studies addressing the problem of hand hygiene, but this study did not take place in a hospital setting. However, participants failed even though they had plenty of time and were not interrupted, which is uncommon in clinical practice. Finally, the fluorescent dye may alter the technique; however, several products have been tested during a 2-year period without finding major changes in technique after adding dye (data not shown).

Technique of applying the alcohol handrub strongly influences antimicrobial effectiveness, and is of crucial importance. Major deficiencies were detected among even highly trained infection control professionals, providing ample evidence for the need for formal training before switching from handwashing to the use of a waterless alcohol handrub.

\section{REFERENCES}

1. Pratt RJ, Pellowe $C$, Loveday HP, et al. The epic project: developing national evidence-based guidelines for preventing healthcare associated infections. Phase I: Guidelines for preventing hospital-acquired infections. J Hosp Infect 2001;47(suppl 2):S3-S82.

2. Girard R, Amazian K, Fabry J. Better compliance and better tolerance in relation to a well-conducted introduction to rub-in hand disinfection. J Hosp Infect 2001;47:131-137.

3. Widmer AF. Infection control and prevention strategies in the ICU. Intensive Care Med 1994;20(suppl 4):S7-S11.

4. Widmer AF. Replace hand washing with use of a waterless alcohol hand rub? Clin Infect Dis 2000;31:136-143.

5. Voss A, Widmer AF No time for handwashing!? Handwashing versus alcoholic rub: can we afford $100 \%$ compliance? Infect Control Hosp Epidemiol 1997;18:205-208.

6. Boyce JM, Pittet D. Guideline for hand hygiene in health-care settings: recommendations of the Healthcare Infection Control Practices Advisory Committee and the HICPAC/SHEA/APIC/IDSA Hand Hygiene Task Force. Infect Control Hosp Epidemiol 2002;23(suppl):S3-S40.

7. Pittet D, Hugonnet S, Harbarth S, et al. Effectiveness of a hospital-wide programme to improve compliance with hand hygiene. Lancet 2000;356:1307-1312.

8. Pittet D, Dharan S, Touveneau S, Sauvan V, Perneger TV. Bacterial contamination of the hands of hospital staff during routine patient care. Arch Intern Med 1999;159:821-826.

9. Cardoso CL, Pereira HH, Zequim JC, Guilhermetti M. Effectiveness of hand-cleansing agents for removing Acinetobacter baumannii strain from contaminated hands. Am J Infect Control 1999;27:327-331.

10. Wade JJ, Desai N, Casewell MW. Hygienic hand disinfection for the removal of epidemic vancomycin-resistant Enterococcus faecium and gentamicin-resistant Enterobacter cloacae. J Hosp Infect 1991;18:211-218.

11. Girou E, Loyeau S, Legrand P, Oppein F, Brun-Buisson C. Efficacy of handrubbing with alcohol based solution versus standard handwashing with antiseptic soap: randomised clinical trial. BMJ 2002;325:362.

12. Girou E, Oppein F. Handwashing compliance in a French university hospital: new perspective with the introduction of hand-rubbing with a waterless alcohol-based solution. J Hosp Infect 2001;48(suppl A):S55-S57.

13. Reagan DR, Doebbeling BN, Pfaller MA et al. Elimination of coincident Staphylococcus auretus nasal and hand carriage with intranasal application of mupirocin calcium ointment. Ann Intern Med 1991;114:101-106. 